\title{
High density lipoprotein subfractions and paraoxonase 1 in children
}

\author{
Jana Muchová1, Lucia Andrezálová1, Stanislav Oravec², Zuzana Nagyová33, Iveta Garaiova4 \\ and Zdeňka Duračková1 ${ }^{凶}$ \\ IInstitute of Medical Chemistry, Biochemistry and Clinical Biochemistry, Faculty of Medicine, Comenius University, Bratislava, Slovakia; \\ ${ }^{2} 2^{\text {nd }}$ Department of Internal Medicine, Faculty of Medicine, Comenius University, Bratislava, Slovakia; ${ }^{3}$ Juvenalia Paediatric Centre, Dunajská \\ Streda, Slovakia; ${ }^{4}$ Research Department, Cultech Ltd, Unit, Port Talbot SA12 7BZ, UK
}

The Lipoprint system (Quantimetrix Corp., CA, USA), enables the determination of 10 high density lipoprotein (HDL) subfractions in contrast to the $5 \mathrm{HDL}$ subfractions that can be determined by ultracentrifuge analysis. HDL subfractions, and their relationships to the arylesterase (PON1-A) and lactonase (PON1-L) activities of paraoxonase 1 (PON1), together with total-, very low density lipoprotein- and low density lipoprotein (LDL)-cholesterol and LDL subfractions were investigated in the serum of 27 mildly hypercholesterolemic children and $\mathbf{2 1}$ healthy controls. Our results suggest the antiatherogenity of large HDL (L-HDL) subfractions and the atherogenity of small HDL (S-HDL) subfractions in the study groups. However, the relationship between the intermediate HDL (I-HDL) subfractions with the LDL subfractions and other lipoproteins did not suggest that I-HDL subfractions are antiatherogenic. No significant association between PON1-A and the HDL subfractions was found. In contrast, PON1-L activity positively correlated with the antiatherogenic large HDL1 subfraction and negatively with intermediate HDL subfractions 4,5 and 6 . Our results contribute to the knowledge of the roles of total HDL and ten individual HDL subfractions in children and adolescents.

Key words: lipoproteins, LDL-lipoproteins, HDL-lipoproteins, children, paraoxonase 1

Received: 08 December, 2015; revised: 18 February, 2016; accepted: 25 February, 2016; available on-line: 06 June, 2016

\section{INTRODUCTION}

Dyslipoproteinemia in children and adolescents can predict clinical manifestations of atherosclerosis in adulthood and therefore there is a growing demand for lipid screening in childhood (Jehlička et al., 2009; McNeal et al., 2010; Daniels et al., 2011).

Generally, high density lipoprotein (HDL) is characterised as the protective antiatherogenic part of the plasma lipoprotein spectrum, compared with the low density lipoprotein (LDL) family which is generally considered to be the atherogenic lipoprotein population (Oravec et al., 2011). The HDL lipoprotein family represents a highly heterogeneous group of plasma lipoprotein entities, with a density (d) ranging from 1.063-1.21 g/ml. Depending on the separation method used, different subfractions of HDL particles can be detected. When fractioned by ultracentrifugation, human HDL is separated into two major subfractions HDL2 $(\mathrm{d}=1.063-1.125 \mathrm{~g} / \mathrm{ml})$ and HDL3 (d=1.125-1.21 g/ml) (Chapman et al., 1981; Pirillo et al., 2013). Non-denaturing polyacrylamide gradi- ent gel electrophoresis divides HDL2 and HDL3 into 5 subfractions: HDL2b ( $\mathrm{d}=1.063-1.087 \mathrm{~g} / \mathrm{ml})$, HDL2a $(\mathrm{d}=1.088-1.110 \mathrm{~g} / \mathrm{ml})$, HDL3a (d=1.110-1.129 g/ml), HDL3b ( $=1.129-1.154 \mathrm{~g} / \mathrm{ml})$ and HDL3c $(\mathrm{d}=1.154$ $1.170 \mathrm{~g} / \mathrm{ml}$ ) (Rosenson et al., 2011).

The Lipoprint LDL and HDL system (Quantimetrix) (Hoefner et al., 2001; Neyer et al., 2003), allows the differentiation up to seven LDL and ten HDL subfractions.

Subfractions HDL1 to HDL10 can be divided into: (i) antiatherogenic large HDL subfractions (L-HDL1 to L-HDL3), (ii) intermediate HDL subfractions (I-HDL4 to I-HDL7) which are at present considered a protective part of HDL and (iii) atherogenic small HDL subfractions (S-HDL8 to S-HDL10) (Morais, 2005; Després, 2007; Oravec et al., 2011a).

Large HDL (L-HDL) subfractions are considered the most protective for arteries (Muniz \& Morais, 2005; Oravec et al., 2011a), intermediate HDL (I-HDL) subfractions of HDL spectrum according to some authors also represent a protective part of spectrum, but small HDL (S-HDL) subfractions may contribute to introduce an atherogenic part of the HDL family (Asztalos et al., 2004; Després, 2007).

The atherogenic LDL lipoprotein profile is characterised by the presence of atherogenic lipoproteins comprising very low density lipoprotein (VLDL), intermediate density lipoproteins (IDL1, IDL2), and the presence of strongly atherogenic small dense lipoproteins (LDL 3-7) (Rajman et al., 1996; Lamarche et al., 1997). IDL3 and LDL1 subfractions are considered to play an antiatherogenic function (Oravec et al., 2011). The protective effects of HDL particles depend on the presence of nonenzymatic proteins (e.g. apolipoprotein A-I) and several enzymes, such as lecithin cholesterol acyltransferase, cholesteryl ester transfer protein, platelet-activating factor, acylhydrolase and paraoxonase 1 (PON1).

PON1 is a calcium dependent glycoprotein esterase, a dimer with molecular weight in the range of $43-45 \mathrm{kDa}$ (Don et al., 1975). In the human, the PON1 gene is located on the long arm of chromosome 7 (Humbert et al., 1993). The PON1 enzyme is found in serum primarily associated with HDL particles (Don et al., 1975). PON1

e-mail: zdenka.durackova@fmed.uniba.sk

Abbreviations: B, boys; BMI, body mass index; $\mathrm{CH}$, cholesterol; CVD, cardiovascular diseses; G, girls; HDL, hight density lipoprotein; $\mathrm{IDL}$, intermediate density lipoprotein; I-HDL, intermediate HDL subfraction; L-HDL, large HDL subfraction;; LDL, low density lipoprotein; LQ, lower quartile; ox LDL, oxidized LDL liupoprotein; ; PON1, paraoxonase 1; PON1-A, arylesterase activity of PON1; PON1-L, lactonase activity of PON1; S-HDL, small HDL subfraction; STRIP, Special Turku coronary Risk factor Intervention Project; TAG, triacylglycerol; TCH, total cholesterol; UQ, upper quartile; VLDL, very low density lipoprotein 
is not bound to LDL particles (James \& Deakin, 2004), although PON1 plays a key role in LDL protection against oxidative damage. The beneficial effect of PON1 in atherosclerosis has been shown to be related to its ability to indirectly reduce oxidative stress by breaking down pro-inflammatory oxidized lipids present in oxidized LDL (oxLDL) in mice (Shih et al., 1998) and this was confirmed through a negative correlation between PON1 activity and the atherogenic index in hypercholesterolemic children (Sumegová et al., 2007). Moreover, decreased PON1 arylesterase activity predicts a higher risk of incidence of long-term adverse cardiovascular events in patients with chronic kidney disease (Kennedy et al., 2013).

It is believed that PON1 acts as (i) a detoxifying enzyme hydrolysing organophosphates (insecticides, neurotoxins) that block the enzyme acetylcholinesterase and (ii) an antiatherogenic enzyme, capable of attenuating plaque formation through the protection of lipoprotein particles from reactive oxygen species by hydrolysing oxidized cholesteryl esters and phosphatidylcholine core aldehydes (Ahmed et al., 2001). The appropriate physiological substrate to use for PON1 assessment is unclear. PON1 displays an appreciable arylesterase activity towards phenyl acetate and a lactonase activity (Jakubowski 2000, Draganov et al., 2005). Lactonase activity has been well documented and homocysteine-thiolactone has been identified as an appropriate physiological substrate of PON1. (Jakubowski, 2000; Khersonsky \& Tawfik, 2005; Jakubowski, 2011). In addition to thiolactone, PON1 exerts hydrolytic activity toward lipolactones (Gaidukov $\&$ Tawfik, 2007) and oxidized phospholipids (Fuhrman et al., 2004). Homocysteine is considered to be a risk factor in atherosclerotic vascular diseases (Racek et al., 2005) through protein homocysteinylation (Perla-Kaján \& Jakubowski, 2012; Jakubowski, 2013). Jakubowski et al. (2015) found that urinary homocysteine-thiolactone is an additional risk predictor of acute myocardial infarction in patients with coronary artery disease independent from established risk factors and plasma total homocysteine level. There have been a limited number of studies on HDL subfractions in children. The STRIP project, which has been running in Finland from 1990 to present, examines the impact of long-term dietary changes and increased physical activity from an early age to adulthood on the prevention of atherosclerosis. The researchers were studying the effect of life-style change on lipid profile, LDL and HDL subfractions in children from age seven onwards. Positive changes in LDL subfractions were found only in boys but HDL subfractions 2 and 3 were unchanged in both genders (Kaitosaari et al., 2009). HDL subfractions have been studied in obese adolescents according to ethnicity (D'Adamo et al., 2010) and African Americans, in contrast to the white race and Hispanics, had reduced large VLDL lipoproteins, reduced small dense LDL subfractions, increased large HDL subfractions and thus lower cardiovascular risk. Differences in lipoprotein subfractions in lean and obese children (7-18 years) found that lean children had higher large HDL subfractions and lower medium LDL and small LDL subfractions in comparison to obese children (Benson et al., 2012). Pietiläinen et al. (2009) investigated HDL subfractions in young twin and found in abdominal overweight children decreased HDL2b and increased HDL3c subfractions independent of genetic influences. A marker for cardiovascular disease, serum amyloid-A was found to be positively correlated with small HDL subfractions in overweight children McEneny et al. (2013).
LDL and HDL subfractions in infants at birth and at 2-3 months of age and in their parents showed an inverse association between the largest HDL subfractions and the small LDL particles (Kwiterovich et al., 2013). At present, the exact function of I-HDL subfractions is not known and their correlations with PON1 or with other HDL associated enzymes have not been discussed.

This pilot study investigates for the first time the relationship between $10 \mathrm{HDL}$ subfractions and lipid profile parameters - TCH (total cholesterol), VLDL (very low density lipoprotein)-cholesterol, LDL-cholesterol, LDL subfractions and to the arylesterase and lactonase activities of paraoxonase 1 in a group of mildly hypercholesterolemic children and adolescents and in healthy children together with any gender link.

\section{SUBJECTS AND METHODS}

Subjects. The subjects and study design are described elsewhere (Garaiova et al., 2013). Briefly, thirty children and adolescents with dyslipidemia, registered with Juvenalia Pediatric Centre, Dunajská Streda, Slovakia, were invited to participate in the study based on the universal screening of cholesterol and glycemia in children aged 11 and adolescents aged 17 according to Ministry of Health guidelines MZ13010/2004. Ethical Approval was granted by the Medical School Ethics Board, Comenius University in Bratislava, Slovakia. Written informed consent was obtained from the parents or guardians before inclusion in the study. Subjects with initial total cholesterol (TCH) levels $\geq 4.1 \mathrm{mmol} / 1$ ( $\geq 159 \mathrm{mg} / \mathrm{dl}$ ) (value recommended by pediatricians in Slovakia according to Šoltésová \& Hrebík, 2006), despite having completed a 3 months period of assigned dietary lifestyle change were selected for inclusion in this study. Genetic diagnosis of familial hypercholesterolemia or familial combined hyperlipidemia had not been determined in any child included in the study. None of the subjects had received lipid or cholesterol lowering drugs, were diabetic, hypertensive or had a history of cardiovascular diseases (Garaiova et al., 2013).

Baseline samples were not provided by three children. The serum of twenty seven children (19 girls, 8 boys) was analysed for lipid profile, HDL subfractions and PON1 activities.

Twenty-one healthy children and adolescents registered in Pediatric Centre Juvenalia, s.r.o Dunajská Streda with average age $14.5 \pm 2.8$ years ( 8 boys and 13 girls) were enrolled into the control group.

Clinical and anthropometric assessment. Body weight and height were measured without shoes and with light clothing using a digital weighing and measuring station with automatic body mass index (BMI) calculation $\left(\mathrm{kg} / \mathrm{m}^{2}\right.$, SECA 764, Germany).

Biochemical analysis. Venous blood samples were collected after 12-hours overnight fast. Within $1 \mathrm{~h}$ of collection, blood was centrifuged $(1200 \times g, 10 \mathrm{~min})$, serum was obtained, aliquoted and frozen at $-80^{\circ} \mathrm{C}$ until analysis. The fasting serum analysis of triacylglycerols (TAG), total cholesterol and glucose were determined using a Hitachi 911 Analyser by standard procedure using Roche Diagnostics kits (Switzerland). The analysis of the HDL subfractions in serum, which included large HDL, intermediate HDL and small HDL, was performed by the Lipoprint HDL system (Quantimetrix Corp., CA, USA) (Muniz \& Morais, 2005) on polyacrylamide gel electrophoresis. HDL subfractions are expressed as \% of area under the curve and in $\mathrm{mg} / \mathrm{dl}$ for the sum of the large, intermediate and small HDL 
Table 1. Baseline characteristics of individuals and PON1 activities

\begin{tabular}{|c|c|c|c|c|c|c|c|c|c|}
\hline \multirow{3}{*}{ Parameter } & \multicolumn{4}{|l|}{ Patients } & \multicolumn{4}{|l|}{ Controls } & \multirow{3}{*}{$\begin{array}{l}P \text { value } \\
\text { Patiens/ } \\
\text { Controls }\end{array}$} \\
\hline & All & Boys & Girls & $P$ value & All & Boys & Girls & $P$ value & \\
\hline & $n=27$ & $\mathrm{n}=8$ & $\mathrm{n}=19$ & $B / G$ & $n=21$ & $n=8$ & $n=13$ & $B / G$ & \\
\hline Age (years) & $16.26(3.34)$ & $15.38(3.11)$ & $16.68(3.35)$ & 0.354 & $14.5(2.78)$ & $14.40(3.11)$ & $14.60(2.68)$ & 0.870 & 0.058 \\
\hline Weight (kg) & $61.69(19.9)$ & $75.31(26.9)$ & $55.95(13.2)$ & 0.02 & $55.4(18.4)$ & $56.1(21.25)$ & 54.89 (17.19) & 0.89 & 0.239 \\
\hline BMI $\left(\mathrm{kg} / \mathrm{m}^{2}\right)$ & $22.41(5.24)$ & $25.39(5.8)$ & $21.16(4.58)$ & 0.055 & $20.5(4.1)$ & 20.05 (3.04) & $20.84(4.78)$ & 0.68 & 0.159 \\
\hline $\mathrm{TCH}(\mathrm{mmol} / \mathrm{l})$ & $5.40(1.17)$ & $4.67(1.33)$ & $5.73(0.95)$ & 0.009 & $3.85(0.59)$ & $3.89(0.76)$ & $3.82(0.48)$ & 0.736 & 0.0001 \\
\hline TAG (mmol/l) & $1.38(0.53)$ & $1.48(0.68)$ & $1.34(0.47)$ & 0.554 & $0.81(0.26)$ & $0.70(0.23)$ & $0.88(0.27)$ & 0.126 & 0.0001 \\
\hline $\begin{array}{l}\text { Fasting Glu- } \\
\text { cose }(\mathrm{mmol} / \mathrm{l})\end{array}$ & $4.9(0.5)$ & $5.43(0.43)$ & $4.71(0.33)$ & 0.0001 & $4.88(0.45)$ & $5.06(0.34)$ & $4.77(0.49)$ & 0.157 & 0.791 \\
\hline $\begin{array}{l}\text { PON1 - } \\
\text { A (U/ml) }\end{array}$ & $134.1(26.2)$ & $141.1(26.9)$ & $131.2(26.1)$ & 0.38 & $122.70(23.9)$ & $\begin{array}{l}127.00 \\
(26.9)\end{array}$ & $119.82(24.7)$ & 0.525 & 0.133 \\
\hline $\begin{array}{l}\text { PON1 - } \\
\mathrm{L}(\mathrm{U} / \mathrm{ml})\end{array}$ & $11.3(2.2)$ & $10.9(1.9)$ & $11.4(2.4)$ & 0.60 & $10.6(2.7)$ & $11.5(2.5)$ & $10.1(2.8)$ & 0.262 & 0.357 \\
\hline
\end{tabular}

Data presented as mean (standard deviation); $\mathrm{n}$, number of subjects per group. BMI, body mass index $\left(\mathrm{BMI}=\right.$ weight $/$ height $\left.{ }^{2}\right) ; \mathrm{TCH}$, total cholesterol; TAG, triacylglycerols; PON1-A, arylesterase activity of PON1; PON1-L, lactonase activity of PON1; B, boys; G, girls; P, significance

subfractions. The data generated from the hypercholesterolemic children were compared with healthy control group.

Arylesterase activity of PON1 (PON1-A). For spectrophotometric determination of PON1-A activity in serum, phenyl acetate was used as the substrate according to Gan et al. (1991). Briefly, addition of $100 \mu$ l of 10 $\mathrm{mmol} / \mathrm{l}$ substrate solution to the assay mixture containing $10 \mu \mathrm{l}$ of diluted serum and $890 \mu \mathrm{l}$ Tris buffer $\mathrm{pH} 8$ (the total volume of the reaction mixture was $1 \mathrm{ml}$ ), production of phenol was detected after 2 min at $270 \mathrm{~nm}$. Spontaneous hydrolysis of phenyl acetate was negligible. The molar extinction coefficient $1310 \mathrm{~mol}^{-1} \cdot \mathrm{dm}^{3} \cdot \mathrm{cm}^{-1}$ was used for the expressing of enzyme activity $(\mathrm{U} / \mathrm{ml}) .1$ $\mathrm{U}$ is defined as $1 \mu \mathrm{mol}$ of phenol produced per minute.

Lactonase activity of PON1 (PON1-L). For spectrophotometric measurement of PON1-L activity in serum, dihydrocoumarin was used as the substrate. Lactonase activity was determined according to Aviram \& Rosenblat (2008). After addition of $500 \mu \mathrm{l}$ of $2 \mathrm{mmol} / \mathrm{l}$ substrate solution to the assay mixture containing $15 \mu$ l of diluted serum and $485 \mu \mathrm{l}$ of Tris buffer $\mathrm{pH} 7.5$ (the total volume of the reaction mixture was $1 \mathrm{ml}$ ), the absorbance was measured within 4 minutes at $270 \mathrm{~nm}$.

For calculation of PON1 activity corrections for spontaneous hydrolysis of the substrate were done. The molar extinction coefficient $1295 \mathrm{~mol}^{-1} \cdot \mathrm{dm}^{3} \cdot \mathrm{cm}^{-1}$ was used for the expressing of enzyme activity $(\mathrm{U} / \mathrm{ml}) .1 \mathrm{U}$ is defined as $1 \mu \mathrm{mol}$ of dihydrocoumarin hydrolysed per minute.

Statistical analysis. Prior to significance testing, the normality of the data was determined using the Shapiro-Wilk test. Data for normally distributed continuous variables are presented as the mean \pm standard deviation (S.D.). The median with minimum, maximum and interquartile range was calculated for variables out of normality. For statistical comparison, P-values were determined using the Student's $t$-test or the Mann-Whitney test. Spearman's rank correlation was used for the correlations between normally distributed data. For values with border statistical significance Kendall's rank correlation was used. $P$-value of $<0.05$ was considered statistically significant. All statistical tests were performed using StatsDirect ${ }^{\circledR}$ version 2.7.9. (Cheshire M33 3UY, UK).

\section{RESULTS}

The baseline characteristics and arylesterase and lactonase activities of PON1 of patient and control groups are shown in Table 1.17 girls from the patients group were menstruating. The patients differed from the control group in TCH and TAG; these parameters were higher in the patients group. Analysis on the basis of gender indicated a significantly higher glucose level in boys $(B)(P=0.0001)$ and higher levels of $\mathrm{TCH}$ in girls $(\mathrm{G})$ in patients group $(P=0.009)$. No gender differences in the control group were observed.

HDL subfraction levels are presented in Table 2. In the patient group the values of subfractions decreased in the order L-HDL2>L-HDL1>L-HDL3 and for I-HDL, I-HDL6>I-HDL4=I-HDL5>I-HDL7. The S-HDL subfractions were the lowest of the three groups comprising S-HDL8>S-HDL9. Subfraction S-HDL10 was not detected in the patients group. No gender differences were observed. 
Table 2. Serum HDL subfractions

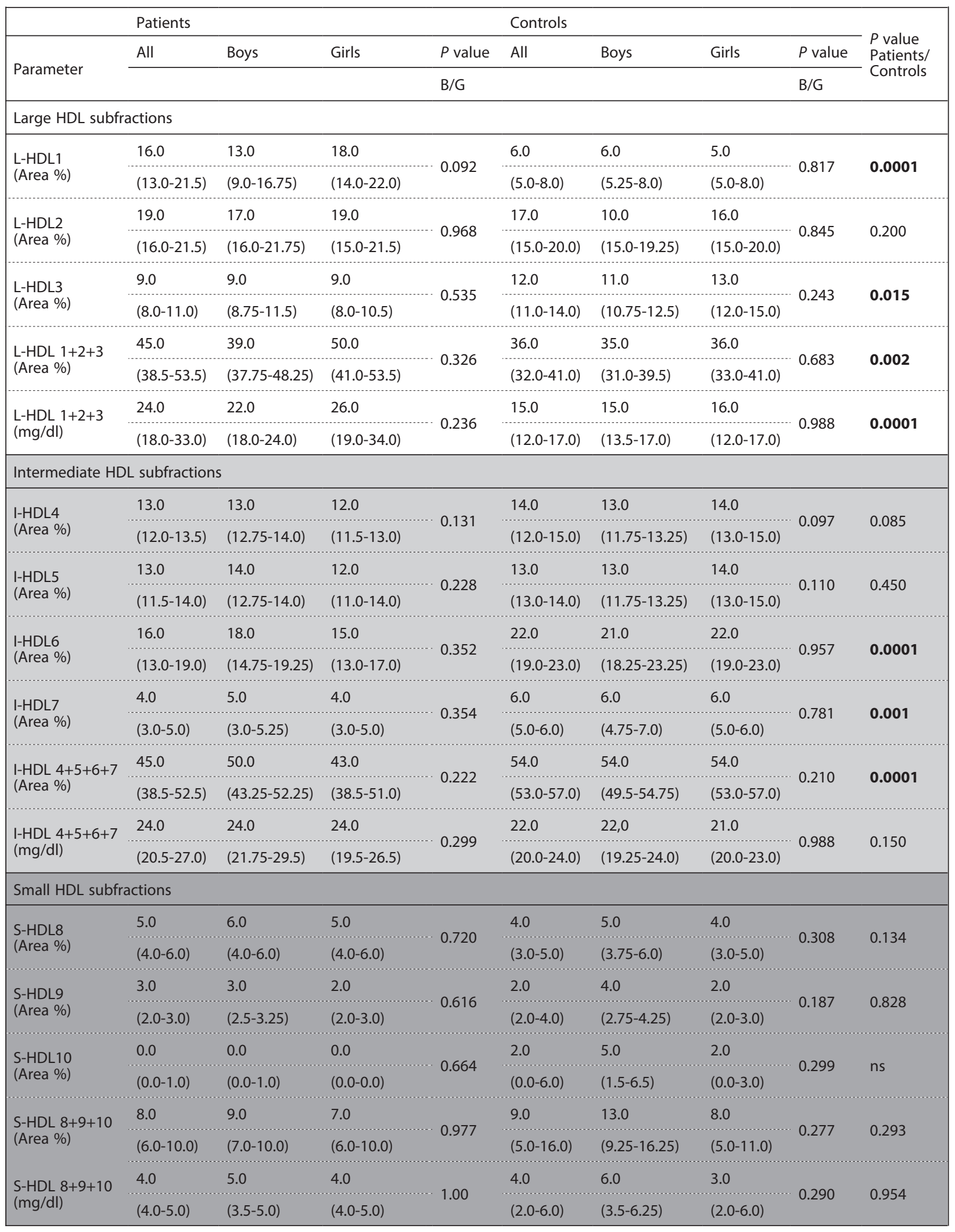

Values are expressed as median with an interquartile range (LQ-UQ; $25-75 \%)$. L-HDL, Large HDL subfraction; I-HDL, Intermediate HDL subfraction; S-HDL, Small HDL subfraction; B, boys; G, girls; LQ, lower quartile; UQ, upper quartile; $\mathrm{P}$, significance; ns, non significant. To change to mmol/I, multiply the values in $\mathrm{mg} / \mathrm{dl}$ with 0.02586 . White colour of lines and columns - nonatherogenic variable. Light grey colour of lines and columns atherogenity/non-atherogenity is not exactly known. Darker grey colour of lines and columns - atherogenic variables 
The most antiatherogenic subfraction L-HDL3 was significantly lower in patients than in the controls. However, L-HDL1 and the sum of the L-HDL subfractions (L-HDL1+2+3) were higher in patients. The levels of the intermediate subfractions I-HDL6 and I-HDL7 and the sum of the I-HDL subfractions (IHDL4+5+6+7) were significantly lower in the patient group than in the controls. The levels of small HDL subfractions were not different from the controls ( $\mathrm{Ta}$ ble 2). In the patient group a trend to higher levels of the nonatherogenic L-HDL1 subfraction was observed in the girls compared to boys $(p=0.092)$. No gender differences were seen for other HDL subfractions in either patients or healthy controls (Table 2). Data for LDL subfractions of this cohort were published previously (Garaiova et al., 2013).

The correlation data presented in Table 3 indicate positive relationships between L-HDL2 and 3 and antiatherogenic IDL3 and between L-HDL3 and HDL$\mathrm{CH}$ in the patient group. No positive correlations were observed for the control group. Negative correlations in the patient group were found between L-HDL2, 3 and $\mathrm{TCH}$, and between L-HDL3 and VLDL-CH as well as LDL2. In the control group negative correlations were found for L-HDL1, 2, 3 and potentially atherogenic LDL2, and between L-HDL1 and VLDL-CH; in the same group a negative correlation was found for LHDL3 and LDL-CH.

For the intermediate subfractions, in the patient group, positive correlations were found for I-HDL5, 6 and TCH and also for I-HDL6 and LDL2. Negative relationship was seen for I-HDL5 and HDL. In the control group, for the intermediate subfractions a positive correlation was seen for I-HDL6, 7 and LDL2 and for I-HLD7 and TCH, LDL-CH, IDL1 and IDL2. Negative correlations were observed between I-HDL4 and both TCH and IDL2 and between I-HDL5 and both LDL$\mathrm{CH}$ and HDL-CH.

S-HDL8, 9 subfractions of the patient group showed a positive correlation with LDL2 (as seen also for IHDL6 in this group) and a positive correlation between S-HDL8 and TCH; a negative correlation between SHDL8, 9 and HDL was seen. In the control group, S-HDL8 showed a positive correlation with LDL-CH contrasting with that seen with I-HDL5. However, as seen for I-HDL7, S-HDL8, 9 had a positive correlation with LDL1 and S-HDL9 also with LDL2. Subfraction SHDL10 also positively correlated with LDL2.

For the patient group a positive correlation was seen for L-HDL1 and PON1-L with negative correlations for the intermediate HDL subfractions 4, 5 and 6. In the control group significant correlations were not seen. No correlation between PON1-A and HDL subfractions was observed.

\section{DISCUSSION}

In this pilot study of the HDL subfractions in hypercholesterolemic children the most antiatherogenic LHDL3 subfraction was decreased in patients when compared to the controls, but the concentrations of L-HDL1 and the sum of the L-HDL subfractions (L-HDL1+2+3) were higher in the patient group than in the controls. The proportions of I-HDL 4 and 5 were comparable with the control group whilst those of I-HDL 6 and 7 were significantly lower in the patient group. Very low levels of the small atherogenic HDL subfractions were detectable.
The HDL lipoproteins are considered to be nonatherogenic in character but the work of Morais and co-workers identified that small HDL subfractions (S-HDL8-10) can be associated with an increased risk of cardiovascular diseases (CVD) (Muniz \& Morais, 2005). Oravec et al. (2011a) observed elevated levels of S-HDL subfractions in adult patients with arterial hypertension and CVD. A review by Superko et al. (2012) on the relationship between HDL subfractions and CVD concluded, that HDL2 (large) and HDL3 (small) analysis alone is insufficient for the assessment of the impact of HDL on CVD and further differentiation of HDL2 and HDL3 is needed. The Quantimetrix Lipoprint system allows separation of HDL into ten subfractions.

There were negative correlations between the antiatherogenic L-HDL2, 3 and TCH and between L-HDL3 and VLDL-CH levels in the patient group as would be expected. No correlation between LDL-CH and the LHDL subfractions was found in the patient group but a negative correlation was seen between L-HDL3 and LDL-CH in the control group.

Positive correlations were recorded between TCH and I-HDL5, 6 and S-HDL8 in the patient group with a negative correlation observed between VLDL-CH and I-HDL4. The HDL-CH showed negative correlations with I-HDL5, 6 and S-HDL8, 9 and a positive correlation with L-HDL3 for the patients whilst in the control group HDL-CH correlated negatively with I-HDL5.

With regard to the HDL subfractions the findings in this study support the view that the proposed antiatherogenic properties of the I-HDL subfractions are questionable. The function of the LDL2 subfractions is also unclear. Oravec et al. (2011b) indicated that the LDL2 subfraction has an atherogenic function and our results support these findings, with a negative correlation between LDL2 and the antiatherogenic L-HDL3 subfraction and a positive correlation with the I-HDL6 subfractions and S-HDL8, 9 in the patient group. In the control group LDL2 correlated negatively with L-HDL1-3 and positively with I-HDL6, 7 and S-HDL9, 10.

The relationships found between atherogenic risk, the HDL or LDL subfractions and their size and functions and PON1 activities are not consistent (Gugliucci et al., 2013). PON1 is associated with HDL but its exact role in relation to the individual HDL subfractions is unclear. Assessments of both HDL subfractions and PON1 activities have some methodological limitations and variations among the data may be related to the use of different analytical techniques, making direct comparisons difficult.

With regard to the HDL fractionation, Kontush et al. (2003) used ultracentrifugation to separate the HDL fractions in serum and found that PON1-A activity increased from large to small HDL subgroups in the order HDL $2 \mathrm{~b}<$ HDL2a $<$ HDL3a $<$ HDL3b $<$ HDL3c. However, when HDL particles were isolated from serum using Fast Protein Liquid Chromatography, PON1-A activity was higher in large compared with small HDL particles. The authors explained this phenomenon by the weak bond between PON1 and HDL2 allowing release of the enzyme from HDL2 during ultracentrifugation. For the HDL3 subfractions, PON1 is more strongly bound and not released during the isolation of the HDL subfractions, as reflected by higher PON1 activity. Gugliucci et al. (2013) reported higher PON1-A activity in isolated HDL3 subfractions and similar results were obtained by Nobécourt et al. (2005) who found a positive correlation between PON1-A activity determined in each subfraction and small dense HDL3 particles isolated by 
Table 3. Correlations between HDL subfractions and lipid parameters, LDL subfractions, PON1-A and PON1-L activities

\begin{tabular}{|c|c|c|c|c|c|c|c|c|c|c|c|}
\hline Parameter & & L-HDL1 & L-HDL2 & L-HDL3 & I-HDL4 & I-HDL5 & I-HDL6 & I-HDL7 & S-HDL8 & S-HDL9 & S-HDL10 \\
\hline \multirow{4}{*}{$\mathrm{TCH}$} & \multirow{2}{*}{ C } & \multirow{2}{*}{ ns } & \multirow{2}{*}{ ns } & $r=-0.370$ & $r=-0.458$ & \multirow{2}{*}{ ns } & \multirow{2}{*}{ ns } & $r=0.501$ & $r=0.418$ & \multirow{2}{*}{ ns } & \multirow{2}{*}{ ns } \\
\hline & & & & $P=0.099$ & $P=0.038$ & & & $P=0.022$ & $P=0.061$ & & \\
\hline & \multirow{2}{*}{$P$} & \multirow{2}{*}{ ns } & $r=-0.664$ & $r=-0.535$ & \multirow{2}{*}{ ns } & $r=0.439$ & $r=0.538$ & \multirow{2}{*}{ ns } & $b=0.295$ & $b=0.289$ & \multirow{2}{*}{ ns } \\
\hline & & & $P=0.0003$ & $P=0.005$ & & $P=0.025$ & $P=0.0051$ & & $P=0.049$ & $P=0.057$ & \\
\hline \multirow{4}{*}{ VLDL-CH } & \multirow{2}{*}{ C } & $r=-0.448$ & \multirow{2}{*}{ ns } & \multirow{2}{*}{ ns } & \multirow{2}{*}{ ns } & \multirow[b]{2}{*}{ ns } & \multirow[b]{2}{*}{ ns } & \multirow{2}{*}{ ns } & \multirow{2}{*}{ ns } & \multirow[b]{2}{*}{ ns } & \\
\hline & & $P=0.043$ & & & & & & & & & ns \\
\hline & $P$ & ns & & $r=-0.383$ & & ns & & & & & \\
\hline & $P$ & ns & ns & $P=0.049$ & $P=0.099$ & ns & ns & ns & ns & ns & ns \\
\hline & $\sigma$ & & & $r=-0.454$ & & $r=-0.467$ & & $r=0.601$ & $r=0.442$ & & \\
\hline $\mathrm{CH}$ & C & ns & ns & $P=0.040$ & ns & $P=0.034$ & ns & $P=0.005$ & $P=0.024$ & ns & ns \\
\hline LDL-CI & $P$ & ns & ns & ns & $\begin{array}{l}r=-0.269 \\
P=0.087\end{array}$ & ns & ns & ns & ns & ns & ns \\
\hline & $C$ & $r=0.431$ & ns & & & $r=-0.473$ & ns & & & & \\
\hline $\mathrm{HOl}-\mathrm{CH}$ & C & $P=0.052$ & ns & ns & ns & $P=0.030$ & ns & ns & ns & ns & ns \\
\hline 10L CI & $P$ & $r=0.307$ & $r=0.344$ & $b=0.301$ & $r=-0.259$ & $r=-0.609$ & $r=-0.492$ & & $r=-0.317$ & $r=-0.416$ & \\
\hline & $P$ & $P=0.059$ & $P=0.079$ & $P=0.036$ & $P=0.096$ & $P=0.001$ & $P=0.01$ & ns & $P=0.053$ & $P=0.032$ & ns \\
\hline & $C$ & ns & ns & $r=-0.434$ & $r=-0.404$ & ns & ns & $r=0.449$ & $r=0.375$ & ns & ns \\
\hline IDL1 & & 113 & (110 & $P=0.051$ & $P=0.071$ & nIs & nis & $P=0.042$ & 0.093 & ns & ils \\
\hline & $P$ & ns & ns & ns & ns & ns & ns & ns & ns & ns & ns \\
\hline & $C$ & $r=-0.400$ & & & $r=-0.501$ & & & $r=0.523$ & $r=0.391$ & & \\
\hline IDI? & C & $P=0.072$ & ns & ns & $P=0.022$ & ns & ns & $P=0.016$ & $P=0.08$ & ns & ns \\
\hline IDLL & & & & $r=-0.303$ & & & & & & & \\
\hline & $P$ & ns & ns & $P=0.062$ & ns & ns & ns & ns & ns & ns & ns \\
\hline & C & ns & $\mathrm{ns}$ & ns & ns & ns & ns & ns & ns & ns & ns \\
\hline ILD3 & $P$ & ns & $r=0.460$ & $r=0.342$ & $n c$ & $r=-0.304$ & $r=-0.284$ & $\mathrm{nc}$ & & & nc \\
\hline & $P$ & ns & $P=0.017$ & $P=0.021$ & ns & $P=0.062$ & $P=0.075$ & ns & ns & ns & ns \\
\hline & C & ns & ns & $r=-0.463$ & ns & ns & ns & $r=0.652$ & $r=0.560$ & $r=0.499$ & ns \\
\hline LDL1 & & & IIS & $P=0.066$ & ils & IIS & His & $P=0.002$ & $P=0.001$ & $P=0.042$ & ns \\
\hline & $P$ & ns & ns & ns & ns & ns & ns & ns & ns & ns & ns \\
\hline & $C$ & $r=-0.536$ & $r=-0.586$ & $r=-0.486$ & & & $r=0.557$ & $r=0.695$ & & $r=0.633$ & $r=0.465$ \\
\hline (?) 2 (ח) & C & $P=0.013$ & $P=0.006$ & $P=0.027$ & ns & ns & $P=0.009$ & $P=0.000$ & ns & $P=0.003$ & $P=0.035$ \\
\hline LUL2 (?) & $p$ & & & $r=-0.463$ & & $r=0.304$ & $r=0.395$ & $r=0.301$ & $r=0.495$ & $r=0.359$ & \\
\hline & $P$ & ns & ns & $P=0.016$ & ns & $P=0.061$ & $P=0.042$ & $P=0.063$ & $P=0.010$ & $P=0.033$ & ns \\
\hline & C & ns & ns & ns & ns & ns & ns & ns & ns & ns & ns \\
\hline LDL3 & $P$ & ns & ns & ns & ns & ns & ns & ns & $\begin{array}{l}r=0.255 \\
P=0.098\end{array}$ & ns & ns \\
\hline PON1-A & C & ns & ns & ns & ns & ns & ns & ns & ns & ns & ns \\
\hline PUIV & $P$ & ns & ns & ns & ns & ns & ns & ns & ns & ns & ns \\
\hline & $C$ & & $r=-0.400$ & & & & $r=0.440$ & & & & \\
\hline$P \cap N 1$ & C & ns & $P=0.082$ & ns & ns & ns & $P=0.052$ & ns & ns & ns & ns \\
\hline PUIVI-L & $p$ & $r=0.388$ & & & $r=-0.403$ & $r=-0.482$ & $r=-0.409$ & & & & \\
\hline & & $P=0.046$ & ns & ns & $P=0.038$ & $P=0.012$ & $P=0.035$ & ns & ns & ns & ns \\
\hline
\end{tabular}

$P$, Patient; $\mathrm{C}$, control; $\mathrm{TCH}$, total cholesterol; VLDL-CH, very low density lipoprotein cholesterol; $\mathrm{LDL}-\mathrm{CH}$, low density lipoprotein cholesterol; HDL$\mathrm{CH}$, high density lipoprotein cholesterol; TAG, triacylglycerols; IDL, Intermediate LDL subfractions; L-HDL, Large HDL subfractions, I-HDL, Intermediate HDL subfractions, S-HDL, Small HDL subfraction; PON1-A, arylesterase activity of Paraoxonase p1; PON1-L, lactonase activity of Paraoxonase $1 ; P$, significance; $r$, Spearman's correlation coefficient; $b$, Kendall's tau coefficient; ns, non significant. WhiSte colour of lines and columns - nonatherogenic variable. Light grey colour of lines and columns - atherogenity/non-atherogenity is not exactly known. Darker grey colour of lines and columns - atherogenic variables 
density gradient ultracentrifugation from type 2 diabetic subjects. Vekic et al. (2007), isolated the subfractions by electrophoresis and found that PON1 activity toward diazoxon was strongly and positively associated with HDL size. Harangi et al. (2009) found in accordance with our results no association between PON1-A and HDL subfractions.

PON1 activity provides an indirect assessment of the antioxidant activity of HDL particles. However, one of the problems with the measurement of PON1 activity is the choice of substrate for assessment. The original studies with PON1 assessed activity against organophosphates using paraoxon as the substrate of choice which would target the detoxifying active site of PON1 but this activity does not play a role in atherogenesis (Perla-Kaján \& Jakubowski, 2012) and it is thought that the arylesterase activity of PON1 provides a better indicator of its antiatherogenic properties. However, it is currently accepted that the lactonase activity of PON1 assessed using homocysteine-thiolactone as the appropriate physiological substrate provides a good assessment of antiatherogenic potential (Aviram and Rosenblat, 2008; Perła-Kaján \& Jakubowski, 2012). PON1 hydrolyses homocysteine-thiolactone and inhibits N-homocysteinylation of proteins that can impair protein function and cause endothelial dysfunction and vascular damage in vivo (Lacinski et al., 2004; Domagala et al., 2006; Perła-Kaján \& Jakubowski, 2010, Macharia et al., 2012). In this pilot study two substrates (phenylacetate and dihydrocoumarin) were used for the assay but significant correlations with HDL subfractions were observed only from the results obtained assessing the lactonase activity of PON1.

Mascarenhas-Melo et al. (2013) showed in CVD risk patients that the large HDL subfractions negatively correlated with oxLDL and the small HDL subfractions positively correlated with oxLDL. These findings are in accordance with our observed positive correlation between L-HDL1 subfractions and PON1-L. However, PON1 itself does not exert direct antioxidant properties (Teiber et al., 2004; Draganov et al., 2005; Perła-Kaján \& Jakubowski, 2012) and it is assumed that its role in oxidative stress (which contributes to atherogenesis) is indirect though elimination of homocysteine-thiolactone and the inhibition of protein N-homocysteinylation (Perla-Kaján \& Jakubowski, 2010).

Some limitations of our study must be noted. The small sample size might account for some of the marginal significances. Also the uneven distribution of numbers and anthropometrics between boys and girls limits the extent of statistical analysis. Our results contribute to the knowledge of total HDL function as well as HDL individual subfractions functions which could contribute to a to a better understanding of the role of individual HDL subfractions, especially I-HDL, in mild hypercholesterolemic children and adolescents.

\section{CONCLUSIONS}

This is the first time ten HDL subfractions have been assessed using the Lipoprint system in children and adolescents. Our results showed a positive association between the large L-HDL subfractions and the antiatherogenic LDL subfractions and between S-HDL subfractions and atherogenic small LDL subfractions in mild hypercholesterolemic children and adolescent. Associations between the intermediate I-HDL subfractions and other lipoproteins did not indicate a positive association with antiatherogenic lipoproteins. No significant association between PON1-A and the HDL subfractions was found. In contrast, PON1-L activity positively correlated with the antiatherogenic large L-HDL1 subfraction and negatively correlated with intermediate I-HDL subfractions 4, 5 and 6. Our results contribute to the knowledge of the roles of total HDL and the ten individual HDL subfractions (notably intermediate I-HDL subfractions) in children and adolescents.

\section{Acknowledgements and funding}

Authors wish to thank Dr. J. Karácsony MD, P. Lukács MD, L. Chandogová, D. Opálená, O. Rajnoldová, A. Kissová, B. Rásóová and K. Farkasová for excellent technical and clinical assistance and all children and their parents who participated in the study, assoc. prof. I. Waczulíková for the consultation of statistical analysis, Dr. Sue Plummer (Cultech, Ltd, UK) for English correction, Mrs. Lýdia Míková for help with references.

\section{Acknowledgements of financial support}

This study was partly financially supported with VEGA grant $01 / 0703 / 13$ of Ministry of Education of SR, Technology Exploitation Programme from the Welsh Assembly Government, United Kingdom, grant APVV No 15-0063 and Mind and Health, civil association.

\section{Conflict of interest}

Authors declared that they have no competing interests.

\section{REFERENCES}

Ahmed Z, Ravandi A, Maguire GF, Emili A, Draganov D, La Du BN, Kuksis A, Connelly PW (2001) Apolipoprotein A-I promotes the formation of phosphatidylcholine core aldehydes that are hydrolyzed by paraoxonase (PON-1) during high density lipoprotein oxidation with a peroxynitrite donor. J Biol Chem 276: 24473-24481. http://dx.doi.org/10.1074/jbc.M010459200.

Asztalos BF, Cupples LA, Demissie S, Horvath KV, Cox CE, Batista MC, Schaefer EJ (2004) High-density lipoprotein subpopulation profile and coronary heart disease prevalence in male participants of the Framingham Offspring Study. Arterioscler Thromb V asc Biol 24: 2181-2187. http://dx.doi.org/ 10.1161/01.ATV.0000146325.93749. a8.

Aviram M, Rosenblat M (2008) Paraoxonases (PON1, PON2, PON3) analyses in vitro and in vivo in relation to cardiovascular diseases. Methods Mol Biol 477: 259-276. http://dx.doi.org/10.1007/978-160327-517-0-20.

Benson M, Hossain J, Caulfield MP, Damaso L, Gidding S, Mauras $\mathrm{N}$ (2012) Lipoprotein subfractions by ion mobility in lean and obese children. J Pediatr 161: 997-1003. http://dx.doi.org/10.1016/j. jpeds.2012.05.060.

Chapman MJ, Goldstein S, Lagrange D, Laplaud PM (1981) A density gradient ultracentrifugal procedure for the isolation of the major lipoprotein classes from human serum. J Lipid Res 22: 339-358.

D'Adamo E, Northrup V, Weiss R, Santoro N, Pierpont B, Savoye M, O'Malley G, Caprio S (2010) Ethnic differences in lipoprotein subclasses in obese adolescents: importance of liver and intraabdominal fat accretion. Am J Clin Nutr 92: 500-508. http://dx.doi. org/10.3945/ajcn.2010.29270.

Daniels SR, Gidding SS, de Ferranti SD (2011) Pediatric aspects of familial hypercholesterolemias: recommendations from the $\mathrm{Na}$ tional Lipid Association Expert Panel on Familial Hypercholesterolemia. J Clin Lipidol 5: S30-S37. http://dx.doi.org/10.1016/j. jacl.2011.03.453.

Després JP (2007) Cardiovascular disease under the influence of excess visceral fat. Crit Pathw Cardiol 6: 51-59. http://dx.doi.org/10.1097/ HPC.0b013e318057d4c9.

Domagała TB, Lacinski M, Trzeciak WH, Mackness B, Mackness MI, Jakubowski H (2006) The correlation of homocysteine-thiolactonase activity of the paraoxonase (PON1) protein with coronary heart disease status. Cell Mol Biol 52: 4-10. http://dx.doi.org/10.1170/T727. 
Don MM, Masters CJ, Winzor D J (1975) Further evidence for the concept of bovine plasma arylesterase as a lipoprotein. Biochem $J$ 151:625-630. http://dx.doi.org/10.1042/bj1510625.

Draganov DI, Teiber JF, Speelman A, Osawa Y, Sunahara R, La Du BN (2005) Human paraoxonases (PON1, PON2, and PON3) are lactonases with overlapping and distinct substrate specificities. $J$ Lipid Res 46: 1239-1247. http://dx.doi.org/10.1194/jlr.M400511JLR200.

Fuhrman B, Partoush A, Aviram M (2004) Acetylcholine esterase protects LDL against oxidation. Biochem Biophys Res Commun 322: 974978. http://dx.doi.org/10.1016/j.bbrc.2004.08.019.

Gaidukov L, Tawfik DS (2007) The development of human sera tests for HDL-bound serum PON1 and its lipolactonase activity. J Lipid Res 48: 1637-1646. http://dx.doi.org/10.1194/jlr.D600045-JLR200.

Gan KN, Smolen A, Eckerson HW, La Du BN (1991) Purification of human serum paraoxonase/arylesterase. Evidence for one esterase catalyzing both activities. Drug Metab Dispos 19: 100-106.

Garaiova I, Muchová J, Nagyová Z, Mišlanová C, Oravec S, Dukát A, Wang D, Plummer SF, Duračková Z (2013) Effect of a plant sterol, fish oil and $B$ vitamin combination on cardiovascular risk factors in hypercholesterolemic children and adolescents: a pilot study. Nutr J 12: 7. http://dx.doi.org/ 10.1186/1475-2891-12-7.

Gugliucci A, Caccavello R, Kotani K, Sakane N, Kimura S (2013) Enzymatic assessment of paraoxonase 1 activity on HDL subclasses: a practical zymogram method to assess HDL function. Clin Chim Acta 415: 162-168. http://dx.doi.org/10.1016/j.cca.2012.10.044.

Harangi M, Mirdamadi HZ, Seres I, Sztanek F, Molnár M, Kassai A, Derdák Z, Illyés L, Paragh G (2009) Atorvastatin effect on the distribution of high-density lipoprotein subfractions and human paraoxonase activity. Transl Res 153: 190-198. http://dx.doi.org/ 10.1016/j.trsl.2009.01.007.

Hoefner DM, Hodel SD, O’Brien JF, Branum EL, Sun D, Meissner I, McConnell JP (2001) Development of a rapid, quantitative method for LDL subfractionation with use of the Quantimetrix Lipoprint LDL System. Clin Chem 47: 266-274.

Humbert R, Adler DA, Disteche CM, Hassett C, Omiecinski CJ, Furlong CE (1993) The molecular basis of the human serum paraoxonase activity polymorphism. Nat Genet 3: 73-76. http://dx.doi. org/10.1038/ng0193-73.

Jakubowski H (2000) Calcium-dependent human serum homocysteine thiolactone hydrolase. A protective mechanism against protein Nhomocysteinylation. J Biol Chem 275: 3957-3962. http://dx.doi. org/10.1074/jbc.275.6.3957.

Jakubowski H (2011) Quality control in tRNA charging - Editing of homocysteine. Acta Biochim Pol 58: 149-163.

Jakubowski H (2013) Homocysteine in Protein Structure/Function and Human Disease. Chemical Biology of Homocysteine-containing Proteins. Springer. ISBN 978-3-7091-1409-4. http://dx.doi.org/10.1007/978-3-70911410-0.

Jakubowski H, Borowczyk K, Glowacki R, Nygård O (2015) Urinary homocysteine thiolactone predicts acute myocardial infarction in a randomized controlled homocysteine-lowering B-vitamin Trial. Circulation 132: A19250.

James RW, Deakin SP (2004) The importance of high-density lipoproteins for paraoxonase-1 secretion, stability and activity. Free Radic Biol Med 37: 1986-1994. http://dx.doi.org/10.1016/j.freeradbiomed.2004.08.012.

Jehlička P, Stožický F, Mayer O Jr., Varvařovská J, Racek J, Trefil L, Siala K (2009) Asymmetric dimethylarginine and the effect of folate substitution in children with familial hypercholesterolemia and diabetes mellitus type 1. Physiol Res 58: 179-184.

Kaitosaari T, Simell O, Viikari J, Raitakari O, Siltala M, Hakanen M, Leino A, Jokinen E, Rönnemaa T (2009) Tracking and determinants of LDL particle size in healthy children from 7 to 11 years of age: the STRIP Study. Eur J Pediatr 168: 531-539. http://dx.doi. org/10.1007/s00431-008-0780-4.

Kennedy DJ, Tang WH, Fan Y, Wu Y, Mann S, Pepoy M, Hazen SL (2013) Diminished antioxidant activity of high-density lipoproteinassociated proteins in chronic kidney disease. $J$ Am Heart Assoc 2: e000104. http://dx.doi.org/10.1161/JAHA.112.000104.

Khersonsky O, Tawfik DS (2005) Structure-reactivity studies of serum paraoxonase PON1 suggest that its native activity is lactonase. Biochemistry 26: 6371-6382.

Kontush A, Chantepie S, Chapman MJ (2003) Small, dense HDL particles exert potent protection of atherogenic LDL against oxidative stress. Arterioscler Thromb Vasc Biol 23: 1881-1888. http://dx.doi. org/10.1161/01.ATV.0000091338.93223.E8.

Kwiterovich PO, Virgil DG, Chu AY, Khouzami VA, Alaupovic P, Otvos JD (2013) Interrelationships between the concentration and size of the largest high-density lipoprotein subfraction and apolipoprotein C-I in infants at birth and follow-up at 2-3 months of age and their parents. J Clin Lipidol 7: 29-37. http://dx.doi. org/10.1016/j.jacl.2012.09.002.

Lacinski M, Skorupski W, Cieslinski A, Sokolowska J, Trzeciak WH, Jakubowski H (2004) Determinants of homocysteine-thiolactonase activity of the paraoxonase-1 (PON1) protein in humans. Cell Mol Biol (Noisy-le-grand) 50: 885-893.

Lamarche B, Tchernof A, Moorjani S, Cantin B, Dagenais GR, Lupien PJ, Després JP (1997) Small, dense low-density lipoprotein particles as a predictor of the risk of ischemic heart disease in men. Prospective results from the Québec Cardiovascular Study. Circulation 95: 69-75. http://dx. Doi.org/ 10.1161/01.CIR.95.1.69.

Macharia M, Hassan MS, Blackhurst D, Erasmus RT, Matsha TE (2012) The growing importance of PON1 in cardiovascular health: a review. J Cardiovasc Med 13: 443-453. http://dx.doi.org/10.2459/ JCM.0b013e328354e3ac.

Mascarenhas-Melo F, Sereno J, Teixeira-Lemos E, Marado D, Palavra F, Pinto R, Rocha-Pereira P, Teixeira F, Reis F (2013) Implication of low HDL-c levels in patients with average LDL-c levels: a focus on oxidized LDL, large HDL subpopulation, and adiponectin. Mediators Inflamm 2013: 612038. http:/ /dx.doi.org/10.1155/2013/612038.

McEneny J, Blair S, Woodside JV, Murray L, Boreham C, Young IS (2013) High-density lipoprotein subfractions display proatherogenic properties in overweight and obese children. Pediatr Res 74: 279283. http://dx.doi.org/10.1038/pr.2013.93.

McNeal CJ, Dajani T, Wilson D, Cassidy-Bushrow AE, Dickerson JB, Ory M (2010) Hypercholesterolemia in youth: opportunities and obstacles to prevent premature atherosclerotic cardiovascular disease. Curr Atheroscler Rep 12: 20-28. http://dx.doi.org/10.1007/s11883$009-0072-0$.

Morais J (2005) Quantimetrix shows that all HDL subfractions may not protect against heart disease. In: Quantimetrix, June 24. http:// quantimetrix.com/quantimetrix-shows-that-all-hdl-subfractions-maynot-protect-against-heart-disease/.

Muniz N, Morais J (2005) Coronary heart disease. High density lipoprotein subclasses associated with heart disease. Medical Letter on the $C D L$ and FDA, July 31 st.

Neyer G, Muniz N, Morais J (2003) Measurement and distribution of HDL subclasses with the new Lipoprint ${ }^{\circledR}$ HDL method. Clin Chem 49 (6, Pt 2): A168.

Nobécourt E, Jacqueminet S, Hansel B, Chantepie S, Grimaldi A, Chapman MJ, Kontush A (2005) Defective antioxidative activity of small dense HDL3 particles in type 2 diabetes: relationship to elevated oxidative stress and hyperglycaemia. Diabetologia 48: 529-538. http://dx.doi.org/10.1007/s00125-004-1655-5.

Oravec S, Dukát A, Gavorník P, Lovásová Z, Gruber K (2011) Atherogenic normolipidemia - a new phenomenon in the lipoprotein profile of clinically healthy subjects. Neuro Endocrinol Lett 32: 317-321.

Oravec S, Dostal E, Dukát A, Gavorník P, Kucera M, Gruber K (2011a) HDL subfractions analysis: A new laboratory diagnostic assay for patients with cardiovascular diseases and dyslipoproteinemia. Neuro Endocrinol Lett 32: 502-509.

Oravec S, Gruber K, Dostal E, Mikl, J (2011b) Hyper-betalipoproteinemia LDL 1,2: a newly identified nonatherogenic hypercholesterolemia in a group of hypercholesterolemic subjects. Neuro Endocrinol Lett 32: 322-327.

Perla-Kaján J, Jakubowski H (2010) Paraoxonase 1 protects against protein N-homocysteinylation in humans. FASEB J 24: 931-936. http://dx.doi.org/10.1096/fj.09-144410.

Perła-Kaján J, Jakubowski H (2012) Paraoxonase 1 and homocysteine metabolism. Amino Acids 43: 1405-1417. http://dx.doi.org/10.1007/ s00726-012-1321-z

Pietiläinen KH, Söderlund S, Rissanen A, Nakanishi S, Jauhiainen M, Taskinen MR, Kaprio J (2009) HDL subspecies in young adult twins: heritability and impact of overweight. Obesity (Silver Spring) 17: 1208-1214. http://dx.doi.org/10.1038/oby.2008.675.

Pirillo A, Norata GD, Catapano AL (2013) High-density lipoprotein subfractions - What the clinicians need to know. Cardiology 124: 116-125. http://dx.doi.org/10.1159/000346463.

Racek J, Rusňáková H, Trefil L, Siala KK (2005) The influence of folate and antioxidants on homocysteine levels and oxidative stress in patients with hyperlipidemia and hyperhomocysteinemia. Physiol Res 54: 87-95.

Rajman I, Kendall MJ, Cramb R, Holder RL, Salih M, Gammage MD (1996) Investigation of low density lipoprotein subfractions as a coronary risk factor in normotriglyceridaemic men. Atherosclerosis 125: 231-242. http://dx. doi.org/10.1016/0021-9150(96)05881-9.

Rosenson RS, Brewer HB Jr, Chapman MJ, Fazio S, Hussain MM, Kontush A, Krauss RM, Otvos JD, Remaley AT, Schaefer EJ (2011) HDL measures, particle heterogeneity, proposed nomenclature, and relation to atherosclerotic cardiovascular events. Clin Chem 57: 392-410. http://dx.doi.org/10.1373/clinchem.2010.155333.

Shih DM, Gu L, Xia YR, Navab M, Li WF, Hama S, Castellani LW, Furlong CE, Costa LG, Fogelman AM, Lusis AJ (1998) Mice lacking serum paraoxonase are susceptible to organophosphate toxicity and atherosclerosis. Nature 394: 284-287.

Šoltésová M, Hrebík M (2006) Atherosclerosis in childhood and primary prevention (in Slovak). Pediatria (Bratisl) 1: 227-231.

Sumegová K, Nagyová Z, Waczulíková I, Žitňanová I, Duračková Z (2007) Activity of Paraoxonase 1 and lipid profile in healthy children. Physiol Res 56: 351-357. 
Superko HR, Pendyala L, Williams PT, Momary KM, King SB 3rd, Garrett BC (2012) High-density lipoprotein subclasses and their relationship to cardiovascular disease. J Clin Lipidol 6: 496-523. http://dx.doi.org/10.1016/j.jacl.2012.03.001.

Teiber JF, Draganov DI, La Du BN (2004) Purified human serum PON1 does not protect LDL against oxidation in the in vitro as- says initiated with copper or AAPH. I Litid Res 45: 2260-2268. http://dx.doi.org/10.1194/jlr.M400213-JLR20.

Vekic J, Kotur-Stevuljevic J, Jelic-Ivanovic Z, Spasojevic-Kalimanovska V, Topic A, Zelikovic A, Stefanovic A, Zunic G (2007) Association of oxidative stress and PON1 with LDL and HDL particle size in middle-aged subjects. Eur J Clin Invest 37: 715-723. http://dx.doi. org/10.1111/j.1365-2362.2007.01849.x. 